Case Report

\title{
Numerical Investigation of the Collapse of the Steel Truss Roof and a Probable Reason of Failure
}

\author{
Mertol Tüfekci ${ }^{*}$, Ekrem Tüfekci ${ }^{2}$ and Adnan Dikicioğlu ${ }^{2,}$ \\ 1 Department of Mechanical Engineering Imperial College London, Exhibition Road, London SW7 2AZ, \\ UNITED KINGDOM; tufekcime@itu.edu.tr \\ 2 Istanbul Technical University, Faculty of Mechanical Engineering, 34437 Gumussuyu-Istanbul-TURKEY; \\ tufekcie@itu.edu.tr, dikicioglu@itu.edu.tr \\ * Correspondence: tufekcime@itu.edu.tr
}

\begin{abstract}
This study investigates the failure of a roof with steel truss construction of a factory building in Tekirdag in North-western part of Turkey. The failure occurred under hefty weather conditions including thunderbolt, lightning strikes, heavy rain and fierce winds. In order to interpret the reason for the failure, the effects of different combinations of factors on the design and dimensioning of the roof are checked. Therefore, finite element analysis is performed several times under different assumptions and considering different factors aiming to determine the dominant ones that are responsible for the failure. Each loading condition gives out a characteristic form of failure. The scenario with the most similar form of failure to the real collapse is considered as the most likely scenario of failure. Also, the factors included in this scenario are expected to be the responsible factors for the partial collapse of the steel truss structure.
\end{abstract}

Keywords: Steel truss; roof structure; partial collapse; finite element analysis; lightning strike.

\section{Introduction}

Engineers aim to make human life easier and to enhance life quality. Throughout mathematical calculations and experimentation, engineers try to predict the behaviour of a system and make its design accordingly [1]. However, there have been cases that ended up in undesirable ways and some caused financial loss or even costed lives. Hadipriono studied nearly 150 major failures of structures around the world and denoted that the major failures are due to the lateral impact forces [2]. Moreover, Klasson published a survey covering failures of slender roofs [3]. Even the simplest structures, which have the most predictable behaviours, fail under unexpected conditions that exceed the designated safety margins $[4,5]$.

Trusses are one of the most widely used and easy-to-design light structures [6]. They are able to carry very large loads relative to their own weights in very large spans. This is one of the main reasons that truss type of structures are preferred to build roof and bridge structures. The possible loads are standardised to help engineers design the structure in a very simple and straightforward way [7]. The standardised loads can be multiple times greater than the structures' own weight. In the case of unexpectedly excessive loads of accumulated snow or rainwater, failure of the designed structure may be unavoidable [8,9]. Geis et al. studied more than 1000 snow-induced building failure incidents in all over the world [10]. An accumulated mass may cause failure in various ways. Excessive weight loads acting on the structures lead to a different load distribution than the designed distribution due to some members entering the plastic region and/or buckling [11-13].

Also, the loads caused by dynamical effects such as earthquakes could lead to failure [14-16]. Structures are more vulnerable to dynamic loads than static loads [17-19]. A way to improve the performance of structures against the dynamic loads is to add damping to the structure [20]. Earthquakes are not the only sources that cause dynamic loads on structures. One of the main dynamic effects, that may lead to sudden or progressive collapses, is wind [21-24]. Wind is a very significant factor that leads to lateral loads to which building structures are relatively more sensitive 
compared to vertical loads [25] Damage study and seismic vulnerability assessment of existing masonry buildings in Northeast India. Furthermore, fire can also be the main factor that leads to structural failure [26]. Another crucial dynamic effect is a very complicated phenomenon, lightning strike. In order only to understand this phenomenon, some research has been carried out [27-29]. How the mechanical systems are affected by this phenomenon, is another subject that has attracted the attention of researchers [30]. Previous research has shown that a lightning strike may also cause the failure of structures [31]. Lightning is also one of the key points of this study. The combination of these enumerated parameters creates a synergy effect, which increases the resultant influence of the factors so that it becomes greater than a superposition of these contributing load components [32].

There are different types of failure mechanisms as well as different types of reasons for the collapse. One of the most important types of failure mechanisms is fatigue [33]. Fatigue may lead to progressive collapse of the structures [34,35]. Progressive collapse may happen instantly following the changed load distribution of members due to buckling and/or failure of some members [36,37]. But it does not have to happen as the time the initiation of failure of individual members but happens after the failure of a certain number of members failing successively [38,39].

In order to predict the mechanical behaviour of truss type structures and avoid these kinds of collapses, it is necessary to have a deeper and more precise understanding. Therefore, many studies are conducted on truss type of structures using two of the most powerful engineering methods, experimental and numerical method. There have been experimental research focusing on the mechanical behaviour of some specific components and/or structures that are used in trusses $[15,40$ 43]. Elastoplastic behaviour of the trusses are also researched in the past for the same purpose [4446]. Additionally, there have been previous studies attempting to investigate trusses combined with different structures under simpler loading to have a better understanding of the mechanical behaviour of trusses when interacting with some different type of structure [4,47-49]. In the past studies by various researchers real roof structures put through experimental testing in order to obtain mechanical behaviour [15,50,51]. As well as roof structures, real bridges are also used for experimental research $[22,52]$. As it is obvious, not in every case experimentation is possible and/or feasible. Therefore, numerical studies have been conducted to predict the mechanical behaviour as well as predicting a plausible failure. For truss type of structures, finite element method is usually employed for trusses since it is one of the most powerful tools of engineering [14,22,51,53]. Pieraccini et al. studied the collapse of a spatial truss roof of a gym building in North Italy during a moderate snowfall by using finite element method [54]. They reported that the elements and connections made by ductile or brittle materials influenced the bearing capacity of the roof structures as well as the geometric imperfections.

On the other hand, not all the failures occur over the progress that takes time. As mentioned earlier, some collapses occur suddenly under excessive impulsive loadings. This study aims to handle a case, which a sudden partial failure of a steel truss roof of a factory took place under heavy weather conditions in the North-western part of Turkey [8]. The main focus is on developing a plausible theory for the failure by employing numerical analyses performed using the finite element method, which covers various loading conditions and their combinations. Not only the truss roof but also the truss roof with the column supports are analysed. Thus, the results of numerical analyses are used to compare obtained failure modes to real failure considering different criteria for failure. The extreme loads due to the ponding of rainfall or snow accumulation and the temperature shock due to the thunderstorm are considered in the analyses. Even under these potential overloads, no damage has been observed. It is observed that the damage caused by these excessive loads occurred in different regions than the current damage. It has been observed that the damage caused by the temperature change is similar to the current damage.

\section{Theory and Case Study}

Materials and Methods should be described with sufficient details to allow others to replicate and build on published results. Please note that publication of your manuscript implicates that you must make all materials, data, computer code, and protocols associated with the publication available 
to readers. Please disclose at the submission stage any restrictions on the availability of materials or information. New methods and protocols should be described in detail while well-established methods can be briefly described and appropriately cited.

Research manuscripts reporting large datasets that are deposited in a publicly available database should specify where the data have been deposited and provide the relevant accession numbers. If the accession numbers have not yet been obtained at the time of submission, please state that they will be provided during review. They must be provided prior to publication.

Interventionary studies involving animals or humans, and other studies require ethical approval must list the authority that provided approval and the corresponding ethical approval code.

\section{Materials and Methods}

\subsection{Overview of the Structure and the Case}

The building consists of six partitions with different sizes and an administration building. The design and all the relevant details of the structure are provided by the company, which undertook the design and the construction of the building. The steel truss roof structure, which is supported on the steel-reinforced concrete columns, covers a total area of $30180 \mathrm{~m}^{2}$.

The slope of the roof is $1 \%$ in each direction. The parapets of 15 and $25 \mathrm{~cm}$ heights surround the roof which is equipped with the siphonic drainage system. The layout, as well as the damaged parts, which are marked with white colour, of the structure, are presented schematically in Figure 1. As it is shown, the entire structure is made of seven partitions including an administrative office and six halls where the industrial manufacturing took place.

The main dimensions of the unit truss system are presented in Figure 2. The steel carrier system consists of a double-layer truss with a depth of $2 \mathrm{~m}$. The bars of this system have circular tube crosssections with different wall thicknesses and diameters depending on their predicted loads. At both ends of the bars, screw threads are located to enable connecting those members to the mero system. Mero system includes steel spherical parts which have screw holes. It is noted that no eccentricity at nodes is observed after the assembly of the individual members. The blocks are divided from each other with expansion joints.

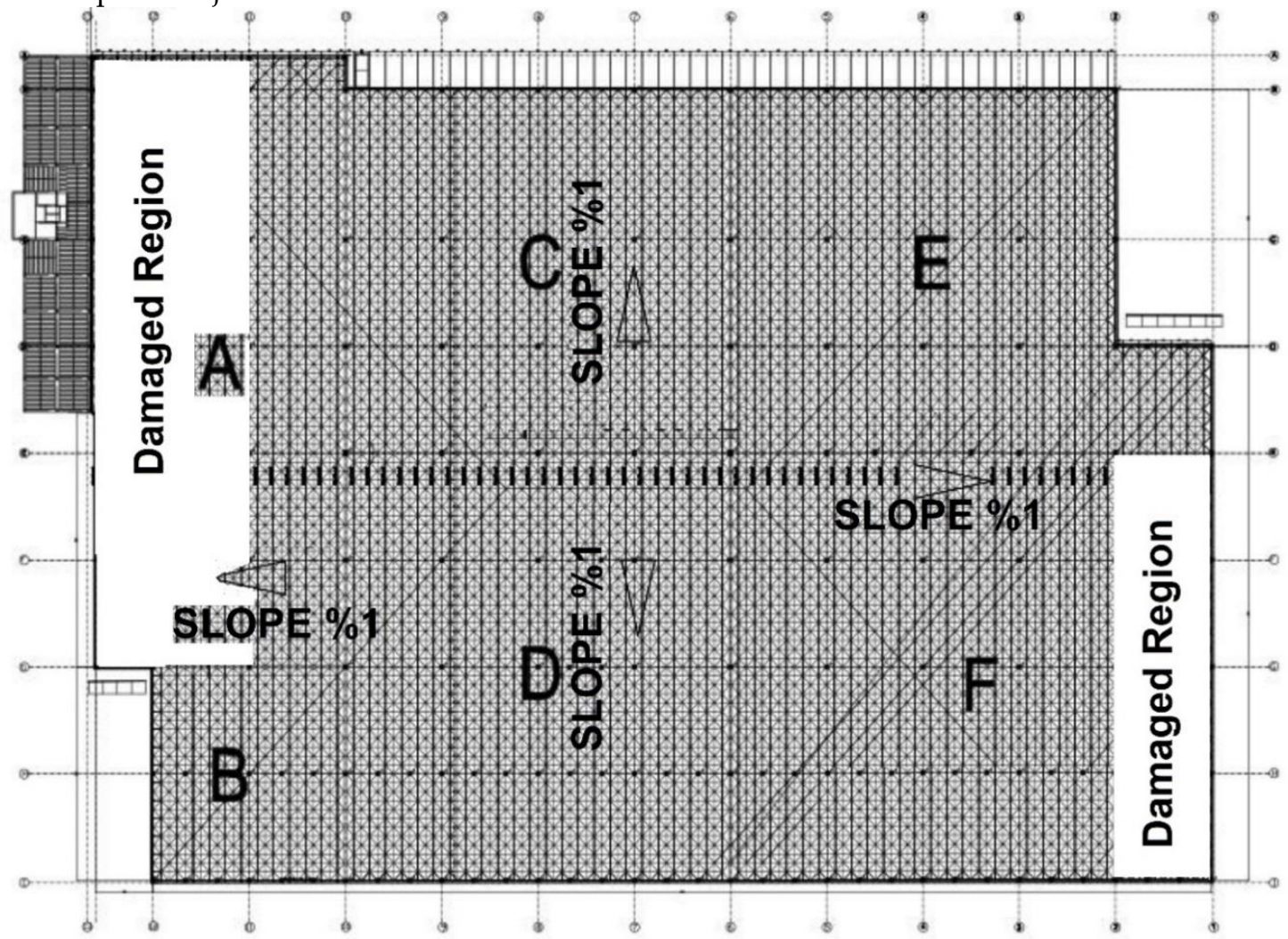

Figure 1. Layout and damaged regions of the roof structure. 


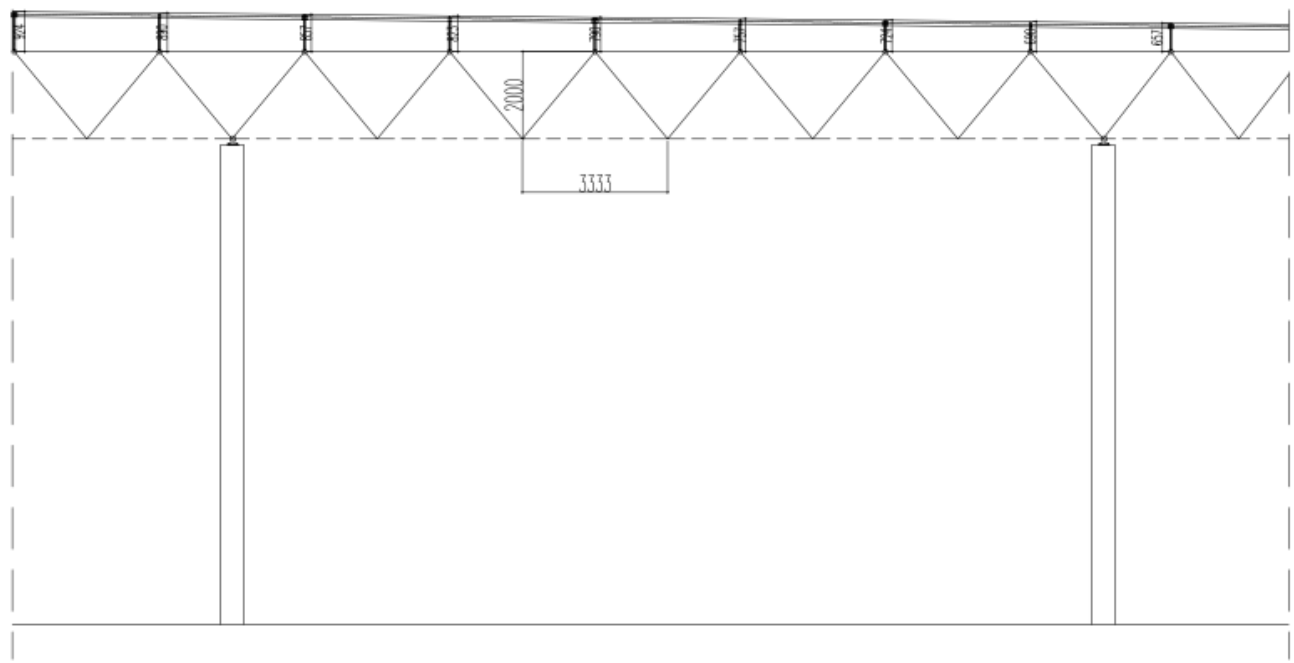

Figure 2. Unit truss structure.

The steel space truss roof structure is mounted on the reinforced concrete columns having $11 \mathrm{~m}$ height and $80 \mathrm{~cm}$ by $80 \mathrm{~cm}$ cross-sections. The number of columns and their configuration can be seen in the plan view of the building which is given in Figure 1. No failure, no deformation and no cracks are observed on these columns during the investigations. Only some broken wings are observed on their top section which is estimated to happen during the collapse of the roof construction. Thus, it is concluded that the columns did not play a significant role in the collapse mechanism of this building. On top of the columns, the spherical joints that are welded to the bearing plates. Figure 3 represents an overview of the real building structure and Figure 4 shows the damaged roof of the space frame system on the night of the incident.

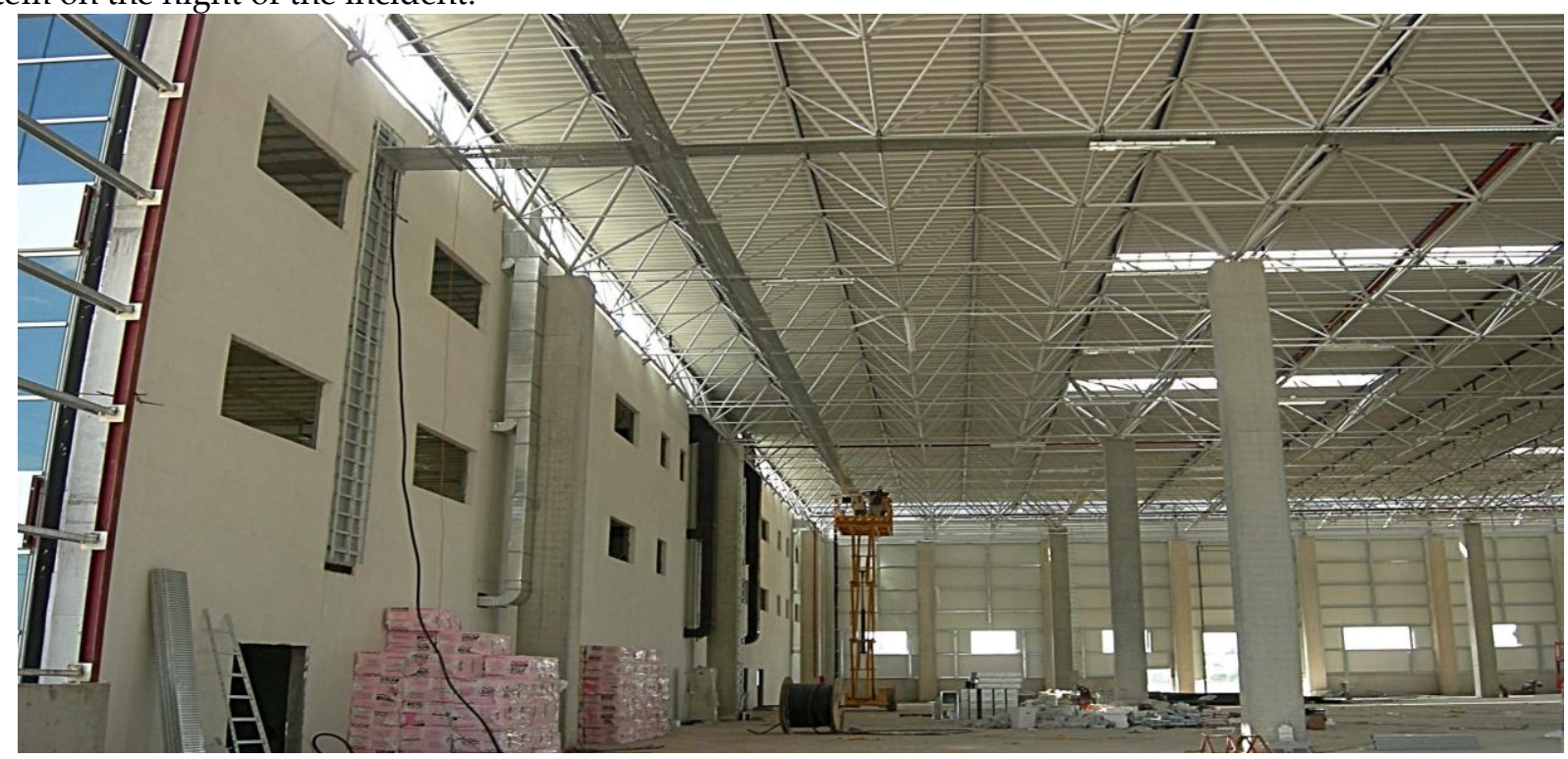

Figure 3. Overview of the roof structure. 


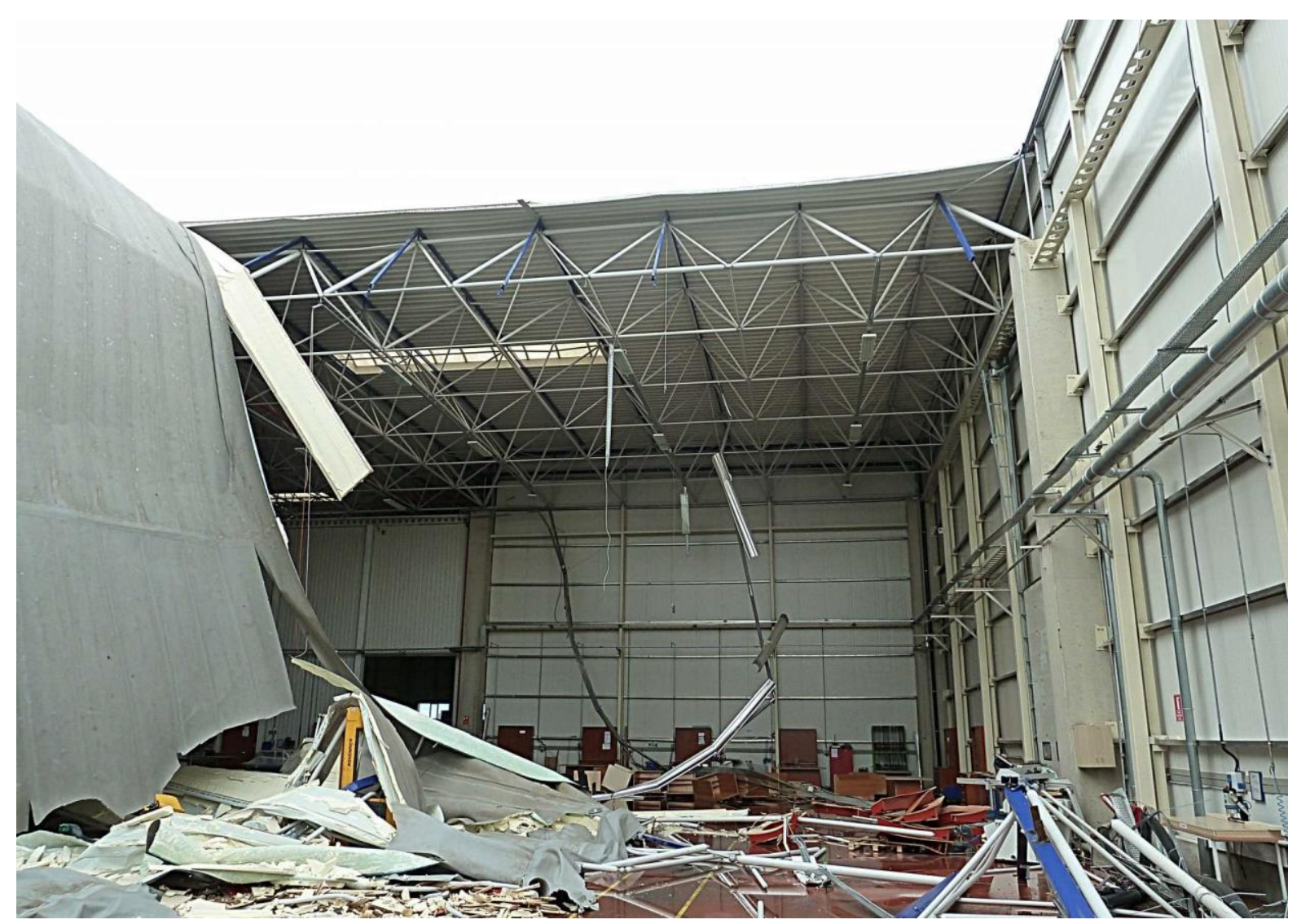

Figure 4. Damage on the roof of the space truss system.

On the day of the incident, more than 500 lightning activities are detected in the region by the British Meteorological Office's (The Met Office) ATDnet (Arrival Time Difference Network) system and the Vaisala Global Lightning Dataset GLD360. It is determined that lightning struck the building and the lightning rods worked. Meteorological data indicate that thunderstorms are rainy and the wind blows from 40 to $60 \mathrm{~km} / \mathrm{h}$ from the north and northeast directions and up to 70 to $80 \mathrm{~km} / \mathrm{h}$ locally. The rainfall is $22.6 \mathrm{~mm}$ during the collapse, although much heavy local rainfalls occurred several times in recent years. Around the roof, there are several siphonic at $5 \mathrm{~cm}$ height. The heights of the parapets on the roof is $15 \mathrm{~cm}$ and $25 \mathrm{~cm}$. Although no scupper is required to be used such shallow parapets, there are several scuppers of $15 \mathrm{~cm}$ height on the roof structure.

\subsection{Structural Members}

The members having steel tube sections with different diameters and thicknesses are used in the truss roof system. The pipe elements with screwed cone ends are connected to the hot forged steel spherical joints. These joints ensured that no eccentricity occurred and the only axial forces are developed in the bars of the truss system. The yield strength of the material (S235JR) of bars and the cone parts at the ends of them (DIN 2458) is $235 \mathrm{MPa}$, ultimate tensile strength is $510 \mathrm{MPa}$ and the allowable stress can be chosen as $144 \mathrm{MPa}$. The bolts used for mounting the bars to the spherical joints are made of 10.9 material quality. The tensile strength of the bolts is $1000 \mathrm{MPa}$ yield strength $900 \mathrm{MPa}$ and the allowable strength is $360 \mathrm{MPa}$ in which the safety factor is 2.5 . The spherical joints used to connect the rods to each other and to the supports are made of hot forged steel with the yield stress of $330 \mathrm{MPa}$ and the tensile strength of $590 \mathrm{MPa}$. The strength values and the chemical decompositions of the materials used in the truss roof system are validated by Piroglu et al [8].

The support spheres are fixed onto the concrete columns by using square or circular plates bolted to the columns. The supports are made of EN C45 steel and Teflon plates are placed under the sliding ones to reduce friction. The details of the joints and supports are given in Figure 5. 

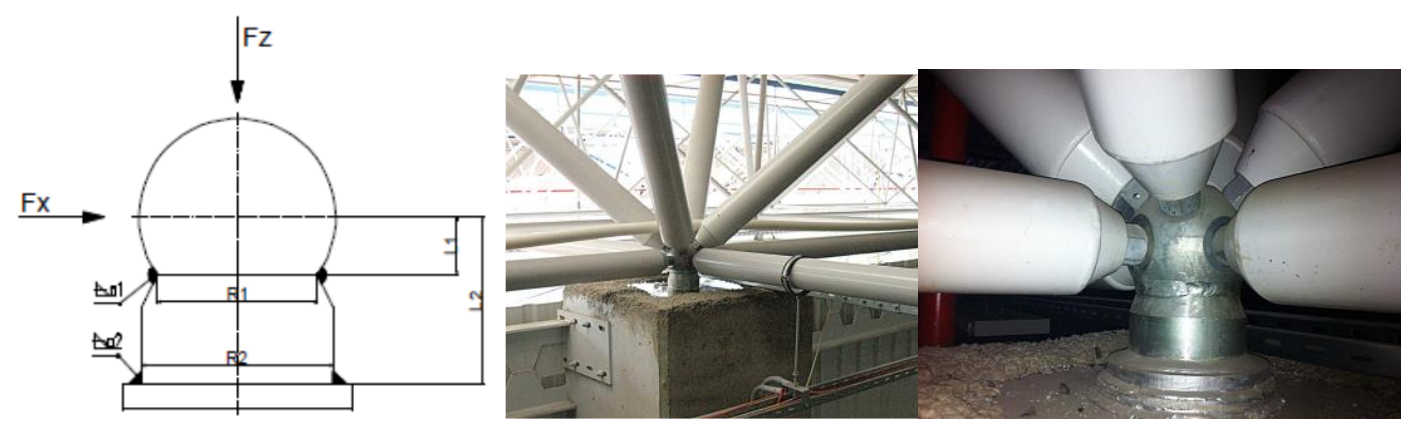

Figure 5. View of the spherical joints and the supports

\section{Analysis}

Two main groups of analysis are performed within the scope of this study. The first group is called the global analysis where the whole load-carrying members of the building are considered as beams and bars while the second group of analysis considers the individual columns and supports.

The first group includes multiple case scenarios with different combinations of loads. Only two major cases are presented in this study for the sake of simplicity.

The second group consists of two stages as well. The first stage investigates the effective material properties of the concrete column reinforced with steel rods under uniaxial tensile strain conditions. Thus, the column is handled as a composite material. The second stage investigates the individual column support connection under the highest forces determined by the global model acting on an individual support.

The three most important material properties, namely Young's modulus (E), Poisson's ratio ( $v$ ) and the thermal expansion coefficient $(\alpha)$ are taken as shown in Table 1.

Table 1. The loads considered in the analyses.

\begin{tabular}{ccc}
\hline Property & Steel & Concrete \\
\hline Young's modulus $(\mathrm{E})$ & $210 \mathrm{GPa}$ & $32 \mathrm{GPa}$ \\
Poisson's ratio $(v)$ & 0.28 & 0.20 \\
Thermal expansion & $13 \mu \mathrm{m} /(\mathrm{m} \mathrm{K})$ & $11.5 \mu \mathrm{m} /(\mathrm{m} \mathrm{K})$ \\
coefficient $(\alpha)$ & & \\
\hline
\end{tabular}

\subsection{Global Analysis}

The given design of the structure is recreated in a compatible CAD format and it is imported into a commercial finite element software. The finite element model is used to simulate some assumptions and certain loading conditions with a consideration of geometric nonlinearities. The boundary conditions and the loads applied to the truss roof system are defined. So, the main purpose of this global analysis is to get a better understanding of the mechanical behaviour and to predict the failure modes under different loads and assumptions. It is worthy to note that all the analyses are run in a static manner. Since the equivalent static loads are determined using the relevant Turkish standards, it is appropriate to use this simplification [8].

One of the most important aspects here is that the presented strength and elastic properties of the materials and members used are put through tests and experimental processes and they have found to be consistent in general [8]. So, in the analyses performed for this study, the values which are presented in the reports of the company will be mainly used.

Different dead, live, snow, temperature and earthquake loads are considered in the design consideration. Rain load caused by an excessive accumulation of water especially on low-slope or flat roofs where the parapets mounted around the roof can dramatically cause partial or total destruction if they are not considered in the design. But, the rainfall ponding on the roof is considered in the design. The design code used gives the wind loads for the buildings of $20-90 \mathrm{~m}$ tall as $0.8 \mathrm{kN} / \mathrm{m}^{2}$ (pressure) on the windward and $-0.4 \mathrm{kN} / \mathrm{m}^{2}$ (suction) on the leeward side. For the seismic loads, the 
earthquake acceleration is taken as $0.3 \mathrm{~g}$, where $\mathrm{g}$ is the gravitational acceleration, so the earthquake loads are overestimated [8].

The loads acting on the space truss system are to be transmitted to the bars over the spherical steel elements called nodes. The weight of the space truss roof system is taken as $140 \mathrm{~N} / \mathrm{m}^{2}$, the dead load from coatings and the installation is given in the design documents as $240 \mathrm{~N} / \mathrm{m}^{2}$ but it is assumed as $350 \mathrm{~N} / \mathrm{m}^{2}$ in the analysis. The snow load is given in the design calculations as $1000 \mathrm{~N} / \mathrm{m}^{2}$ and it is taken as $2000 \mathrm{~N} / \mathrm{m}^{2}$ in the analysis. This load represents two alternative cases. The first case is the excessive snow load and the second is ponding due to rainfall. Around the rooftop surface, there are several scuppers with $15 \mathrm{~cm}$ height. Even with the assumption of full ponding of the roof with $15 \mathrm{~cm}$ height, this load level is not reached. It can be confidently claimed that the chosen load is on the cautious side and will lead to conservative results. The equivalent earthquake horizontal load is given as $180 \mathrm{~N} / \mathrm{m}^{2}$ in the design calculations and it is considered here as $200 \mathrm{~N} / \mathrm{m}^{2}$. Equivalent earthquake vertical load is $950 \mathrm{~N} / \mathrm{m}^{2}$ and the vertical wind load is $960 \mathrm{~N} / \mathrm{m}^{2}$. Table 2 gives the loads used in the analyses.

Table 2. The loads considered in the analyses.

\begin{tabular}{cc}
\hline Load description & Value \\
\hline Own weight of the space truss system & $140 \mathrm{~N} / \mathrm{m}^{2}$ \\
Dead loads & $350 \mathrm{~N} / \mathrm{m}^{2}$ \\
Snow load & $\left(240 \mathrm{~N} / \mathrm{m}^{2}\right.$ given in design calculations $)$ \\
Vertical wind loads & $2000 \mathrm{~N} / \mathrm{m}^{2}$ \\
Equivalent earthquake vertical load & $\left(1000 \mathrm{~N} / \mathrm{m}^{2}\right.$ given in design calculations. $)$ \\
Equivalent earthquake horizontal load & $960 \mathrm{~N} / \mathrm{m}^{2}$ \\
& $950 \mathrm{~N} / \mathrm{m}^{2}$ \\
& $200 \mathrm{~N} / \mathrm{m}^{2}$ \\
\end{tabular}

The boundary conditions of the space truss system and the columns are arranged as the original design of the structure.

The bars of the space truss are modelled based on the standards of DIN S235 JR quality linear elastic materials and columns are modelled as C35 grade homogeneous and linear elastic steelreinforced concrete with the elasticity modulus which is determined using the homogenisation of the composite column analysis. The bar elements in the space truss system and the beam elements in the columns are assembled as the whole system of 160133 elements and 461847 nodes. Figure 6 displays the model for global analysis in a commercial finite element software. With this model, a static global analysis of the space truss system is performed with the above-mentioned loads being quite larger than the design loads. 


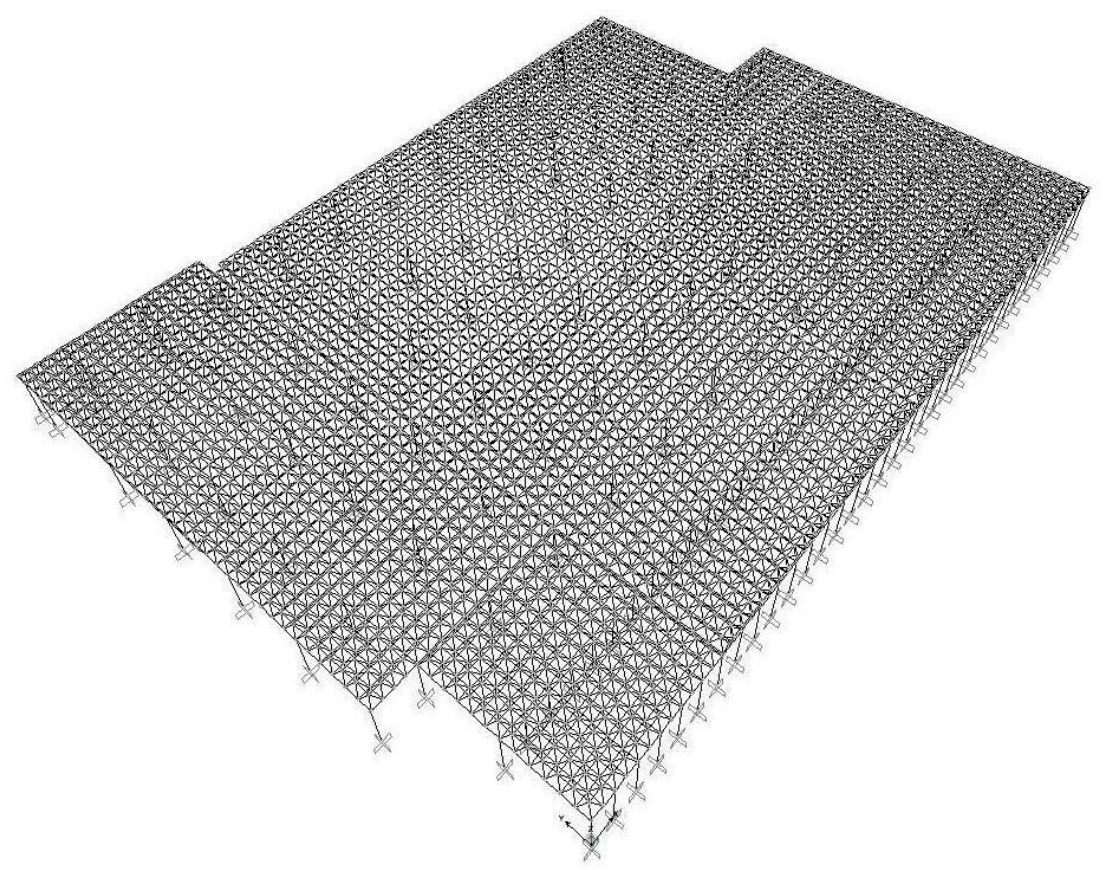

Figure 6. Three-dimensional finite element model prepared for FE analysis.

\subsection{Analysis of the Columns and Supports}

This section covers the analysis performed to gain more insights into the mechanical behaviour of the columns and the supports which either are not very accurately represented in the global model or to increase the accuracy of the global model. The first stage of this group of analysis aims to homogenise the composite column and the second stage investigates the mechanical behaviour of column and support behaviour focusing on the stress/strength of the structure.

\subsubsection{Analysis of the Steel-Reinforced Columns}

The main purpose of this analysis is to understand the effective material properties of the steelreinforced concrete columns by using three-dimensional finite elements. Thus, it is aimed to obtain a more realistic global model. For this purpose, a model is created considering the steel reinforcement of the concrete columns. In this model, the column material is considered as a composite material with concrete and reinforcing steel rods. The steel rods are placed in the concrete as shown in Figure 7. The rods and the concrete are rigidly bonded to each other. According to the general theory of mechanics of composite materials, lateral reinforcement steel binders, which are predicted to have no significant effect on axial stiffness, are not included in the analysis for the sake of simplicity. The steel reinforcing rods are taken as given in the project and as described in the previous section. 


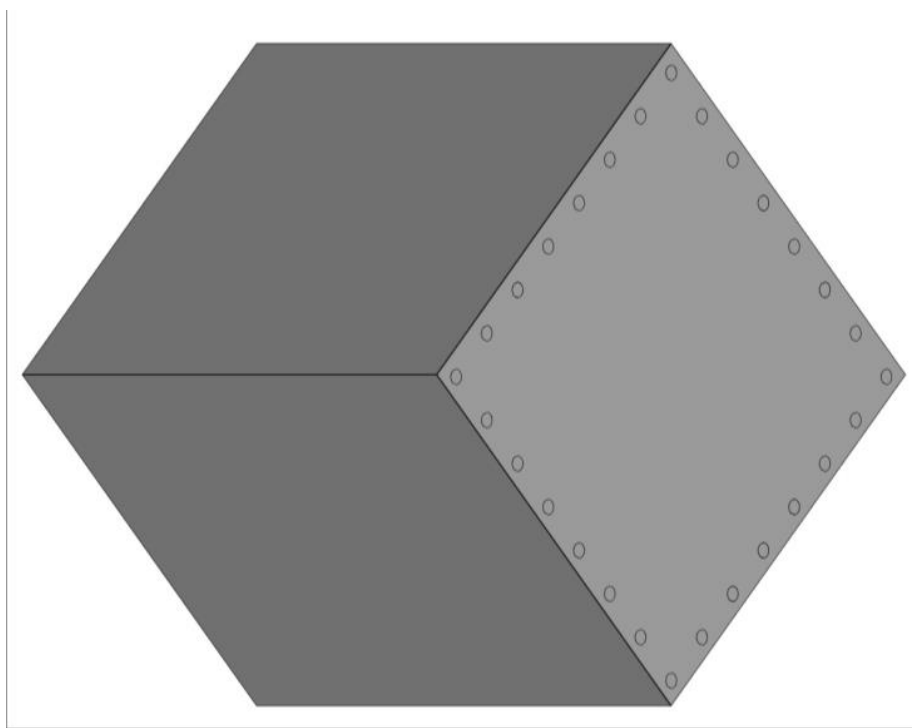

Figure 7. CAD of a column with steel-reinforced concrete.

To represent the behaviour, a cross-sectional face is subjected to axial displacement restrictions whereas the opposite face, which is the other cross-sectional face, is subjected to a uniform axial displacement. Using the results of the analysis the effective Poisson's ratio and Young's modulus are determined. A similar procedure is also performed for the effective thermal expansion coefficient. The results of this analysis are used in the global analysis.

\subsubsection{Analysis of the Spherical Support with Steel-Reinforced Columns}

This part of the study is interested in mechanical behaviour and safety of the column and spherical support structures. This study uses the highest mechanical loads acting on a single trusscolumn connection node calculated in the global analysis. It is also important to note that this analysis considers only the mechanical loads and does not consider any thermal effects. The analysis of the column support connection is performed with a three-dimensional finite element model.

The column support connection is built such that the sphere is mounted on the support plate which is embedded in the steel-reinforced concrete with a bolt connection. The structure of this model is given in Figure 8.

The contact interfaces between the steel rods and concrete are rigidly bonded as well as the contact surfaces between the spherical support and the steel plate. The bolts are attached to the model with a standard preload and connected to the steel plate and concrete with friction.

The bottom cross-sectional face is connected to a grounded spring with 6 degrees of freedom and with the stiffness values of the rest of the column, to save computational time.

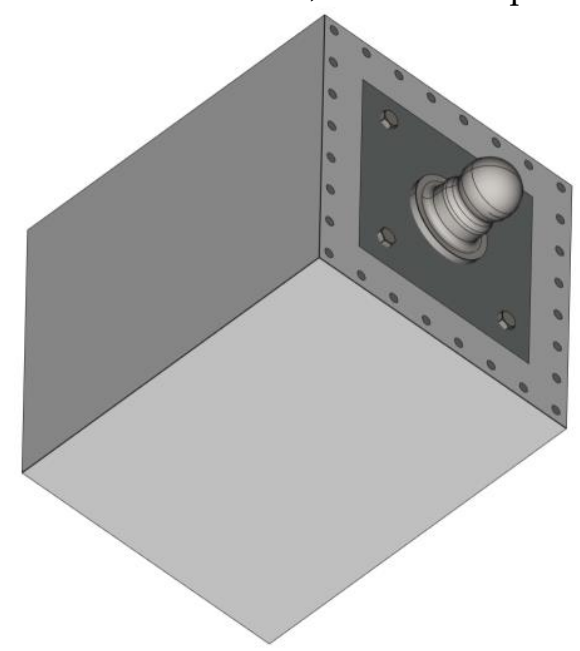

Figure 8. CAD of column support connection with steel-reinforced concrete. 


\section{Results and Discussion}

In this section, the results of the analysis are presented and discussed. Based on the interpretations of the results that match the actual failure form of the structure, a scenario, which is judged the most plausible, is described and discussed.

\subsection{Analysis of the Steel-Reinforced Columns}

The homogenisation study is conducted and the results are presented here. Figure 9 shows the equivalent stress distribution in the case of axial loading of the composite structure and Figure 10 shows displacement distribution. As a result of this analysis, the elasticity modulus and the resultant thermal expansion coefficient of the steel-reinforced concrete are calculated as $48 \mathrm{GPa}$ and $12.8 \mu \mathrm{m} /(\mathrm{m}$ $\mathrm{K})$. This axial elasticity modulus value is used as $50 \mathrm{GPa}$ in global analysis.
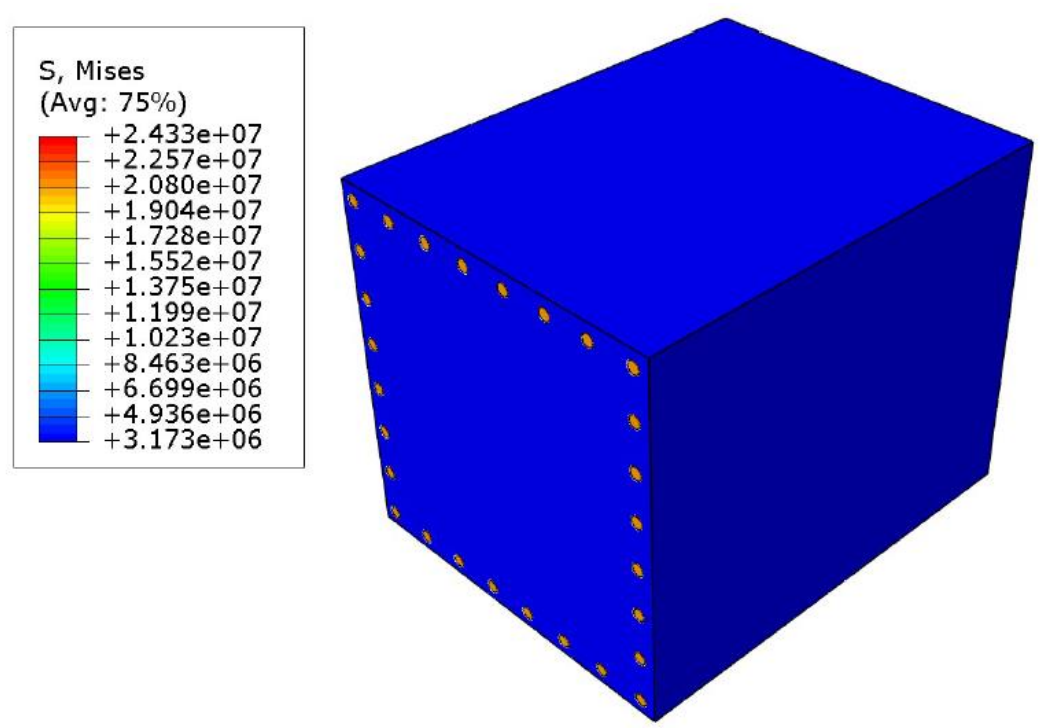

Figure 9. Stress distribution in case of axial stress of steel-reinforced concrete column.
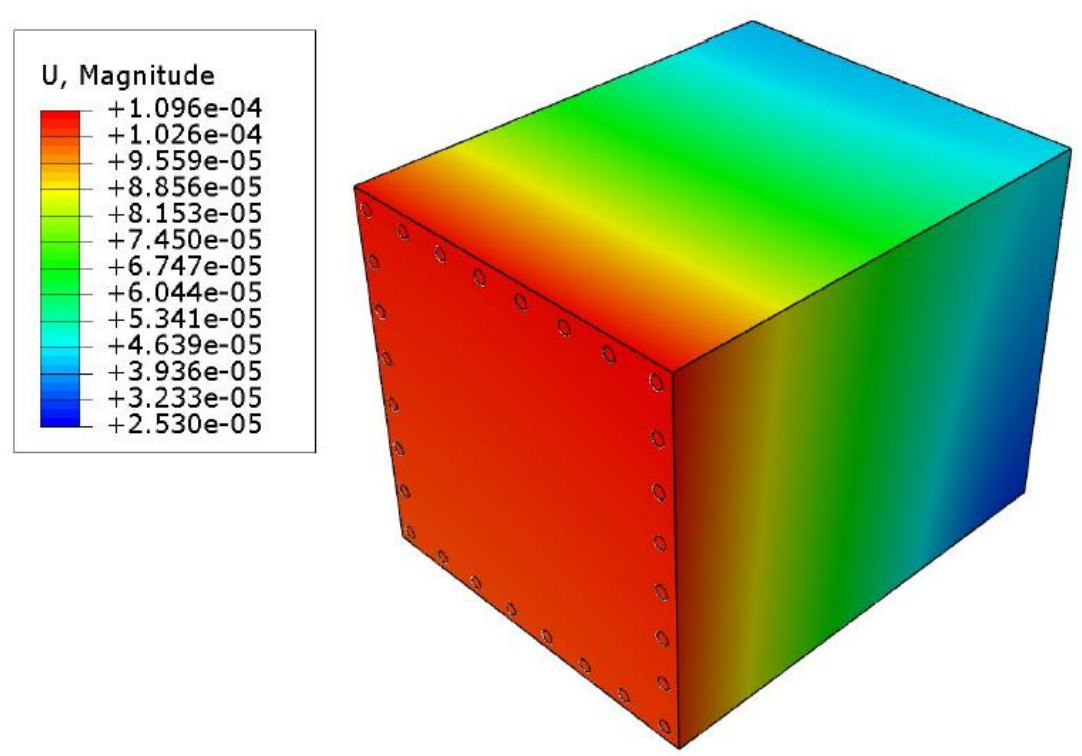

Figure 10. Displacement distribution of steel-reinforced concrete column in case of axial stress. 


\subsection{Global Analysis with only Mechanical Loads}

The displacements and the stresses occurring in the truss roof system are calculated by using the finite element analysis software. Figure 11 shows the resultant displacement (in meters) under the considered loads. The largest displacements being around $4.7 \mathrm{~cm}$ occur in the blocks $\mathrm{A}, \mathrm{C}$ and $\mathrm{E}$ where the gap between the columns is the largest $(28 \mathrm{~m})$, as it is expected. The region of the larger resultant displacements is not where the real damage happened. The deformations of the column structures are so small that they do not point out any safety issues. The analyses demonstrate clearly that the system is safe and that the results are consistent with the results obtained by the engineering bureau.
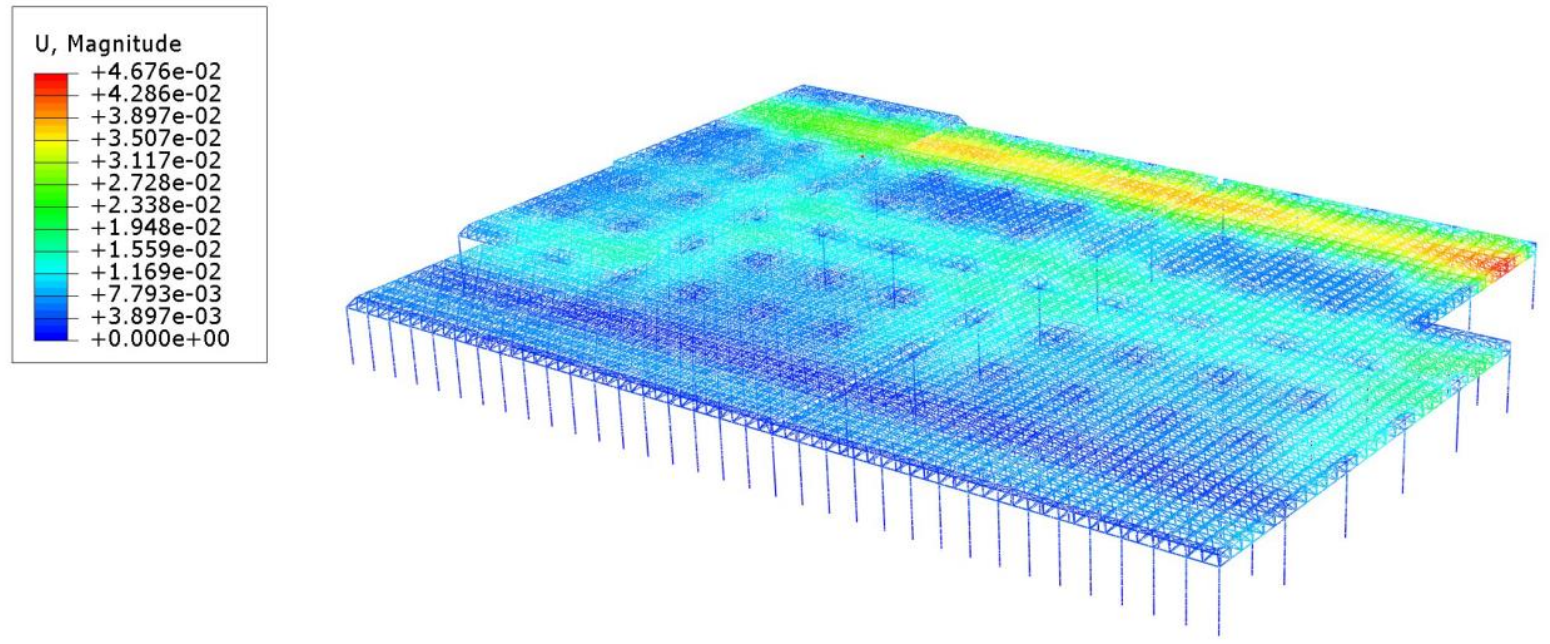

Figure 11. The resultant displacement of steel-reinforced concrete column system.
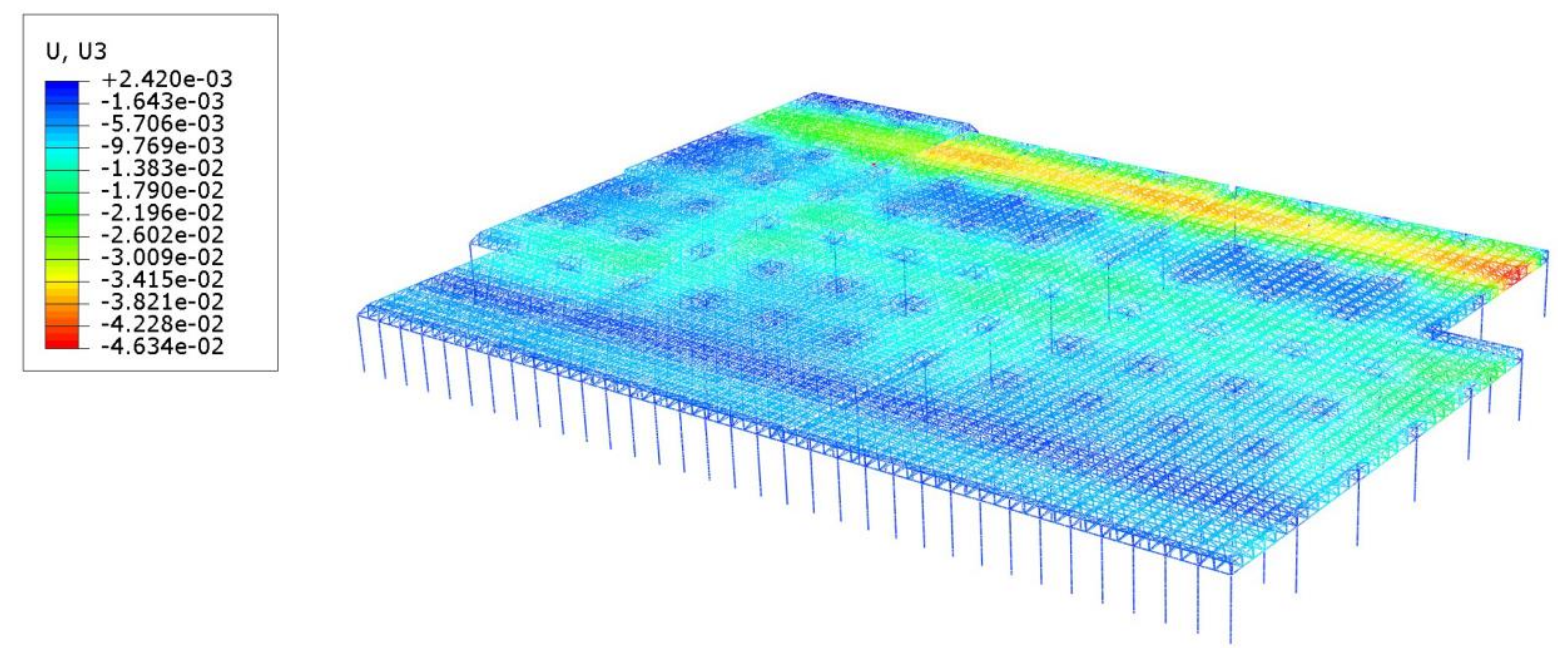

Figure 12. Vertical displacement of the steel-reinforced concrete column system.

Figure 12 shows the vertical displacement results of the same analysis. It should be noted here that due to the positive direction of the axis, which is upwards, blue colours are around zero and red is the largest in terms of absolute values. A, C and E blocks show the largest displacement in the region with the largest column distances. Figures 11 and 12 show the same mode of deformations of the structure, since, among the displacement components, the vertical displacement is the dominant one.

Considering the stress analysis, the equivalent stresses by using von Mises criteria are calculated for all the structure. Figure 13 gives the von Mises stresses in the roof structure (in Pa). It is seen that all stresses of the roof structure together with the columns are within the safety limits. The collapsed 
regions are also within the safety limits. As well as the displacements, the stresses occurring in the column structures are well below the safety limits. Although exaggerated loads are applied on the roof structure, the stresses and displacements in the beams and rods show that the structure would not fail under these combinations of excessive loads.
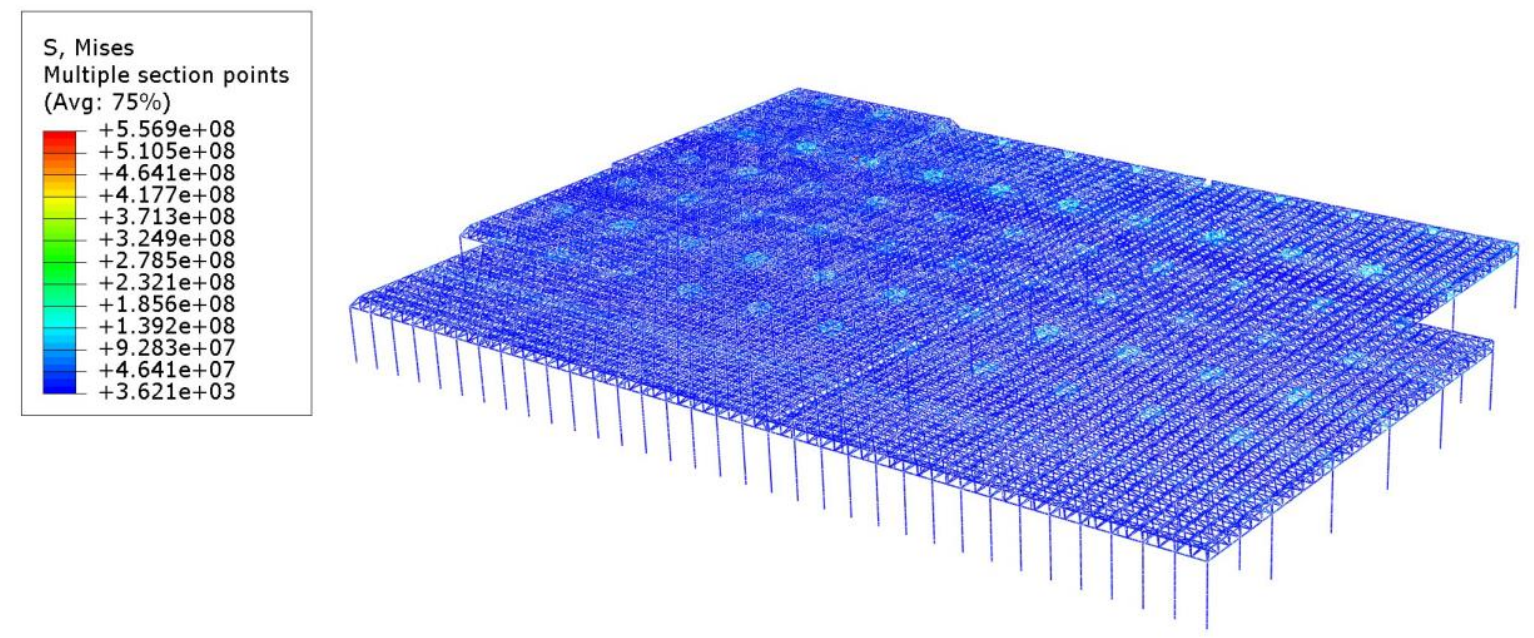

Figure 13. Equivalent von mises stress distribution of steel-reinforced concrete column

The greatest stresses occur at these " $U$ " shaped connections shown in Figure 14. Whereas the displacements are not excessive. It is important to note that, this connection structure does not exist in the real application. These connections are used in the CAD/FE model in order not to distort the dimensions of the truss structure. In reality, there are walls with certain thickness whereas the FE model uses beam elements. To connect the trusses with the supports, such a "dummy" structure is used. Therefore, the stress values that are read at these connections are disregarded.

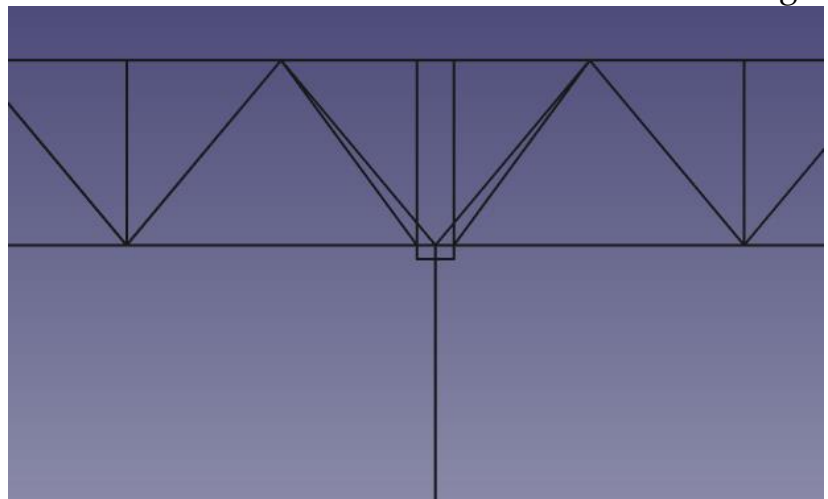

Figure 14. Connections with the supports and steel truss at the block interfaces

\subsection{Analysis of the Spherical Support with Steel-Reinforced Columns}

After finding out that the global structure is safe, the next step is to analyse an individual column support by using the finite element method. The results of the global analysis are used to determine the support reactions. At the most dangerous column support connection, the horizontal force is 95 $\mathrm{kN}$ and vertical force is $940 \mathrm{kN}$. The forces are taken as $120 \mathrm{kN}$ in horizontal and $1000 \mathrm{kN}$ in vertical directions. 


\begin{tabular}{|l|}
\hline S, Mises \\
(Avg: $75 \%$ ) \\
$+2.886 \mathrm{e}+08$ \\
$+2.645 \mathrm{e}+08$ \\
$+2.405 \mathrm{e}+08$ \\
$+2.164 \mathrm{e}+08$ \\
$+1.924 \mathrm{e}+08$ \\
$+1.683 \mathrm{e}+08$ \\
$+1.443 \mathrm{e}+08$ \\
$+1.202 \mathrm{e}+08$ \\
$+9.619 \mathrm{e}+07$ \\
$+7.214 \mathrm{e}+07$ \\
$+4.810 \mathrm{e}+07$ \\
$+2.405 \mathrm{e}+07$ \\
$+2.171 \mathrm{e}+03$ \\
\hline
\end{tabular}

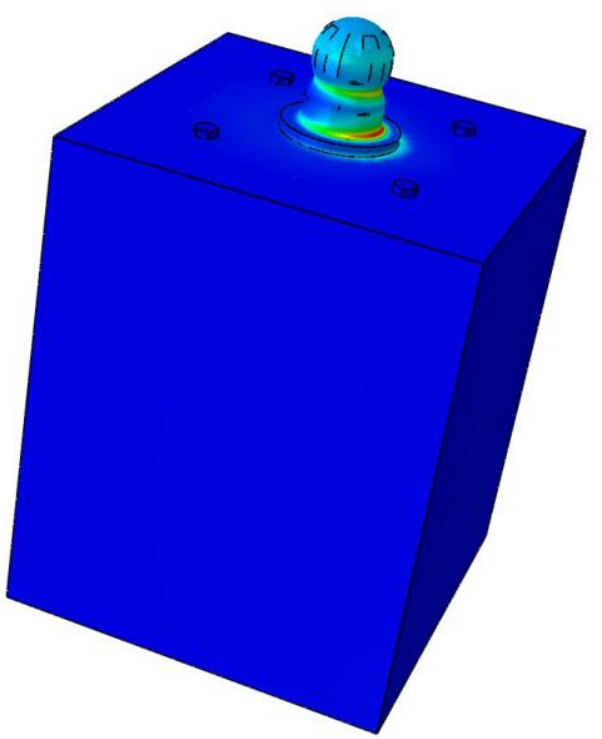

Figure 15. Equivalent stress distribution of column support connection.

The equivalent stress distribution obtained in this case is shown in Figure 15. As it can be clearly seen from this figure, the stress levels are below the yield stress even though extreme loads are applied. Figure 16 shows a post-damage image of one of the columns to which the space frame roof system is attached.

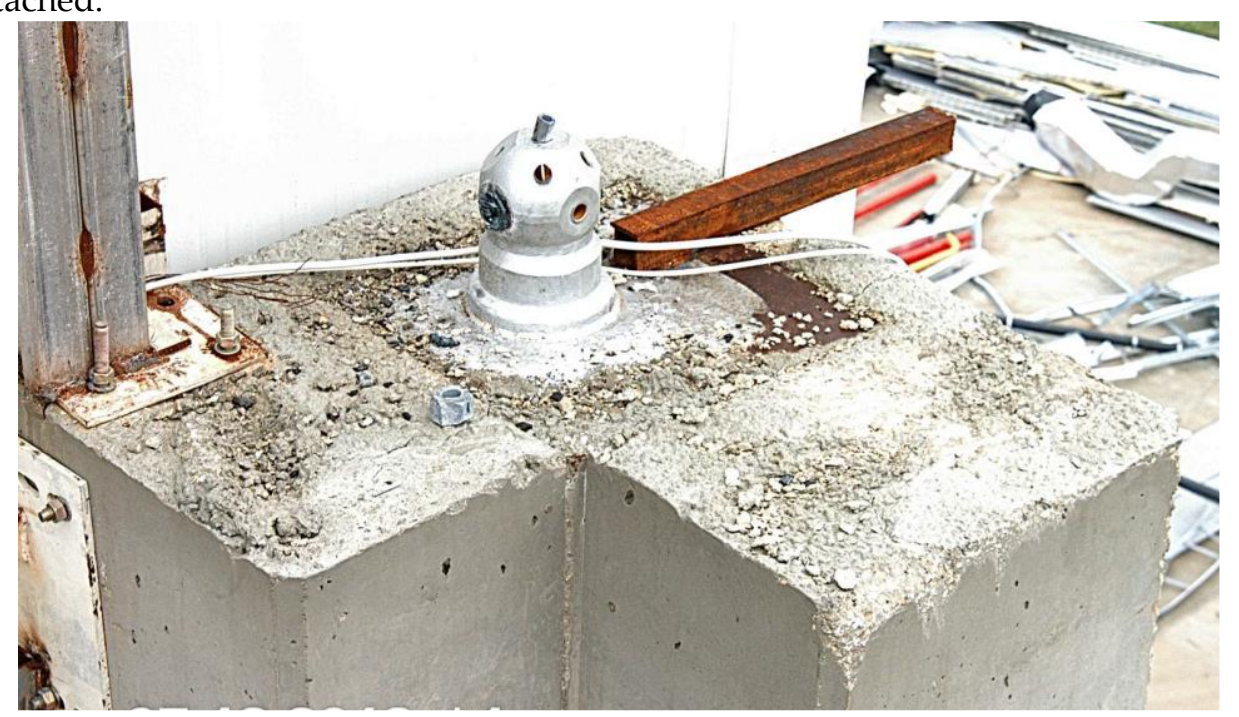

Figure 16. Damage on the support to which the space truss roof system is attached.

Figure 17 shows the distribution of the resultant displacement that occurs in the column support connection. Here, it can be seen that the maximum value of the displacement compounds of the spherical support is around $0.3 \mathrm{~mm}$. 

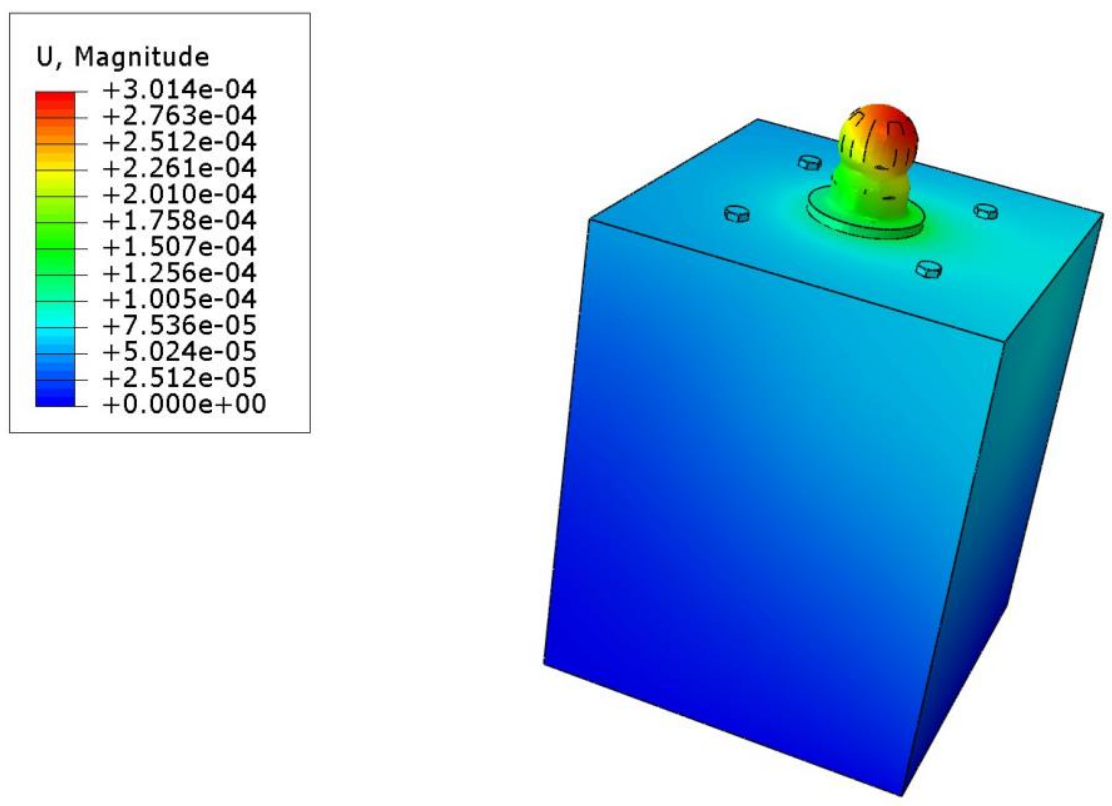

Figure 17. Resultant displacement distribution of column support connection.

\subsection{Global Analysis with Mechanical Loads and Thermal Effects}

With these results obtained from the global analysis it is found that increasing horizontal forces may cause damage, various damage scenarios are investigated by changing the loads applied to the space frame system. As the first case, the vertical load is increased considerably and no damage is predicted in the real damaged zones A and F, as given in Figure 1. As the next case, the structure is tested by increasing the horizontal load. Although the horizontal load value has been increased to a level that cannot be reached by wind and similar factors, the damage occurred cannot be explained with these combinations of loads. However, the structure is found more "sensitive and vulnerable" to the horizontal loads. Finally, it is understood that the space frame system with the columns is safe against vertical loads (snow, water, etc.) and horizontal loads (wind etc.).

It is obvious that different factors must be present in order to explain the real damage in the structure. Therefore, considering the natural events occurring on the night of the event, their effects on the structure are considered. It is interpreted that reasons such as heavy rain that leads to ponding on the roof with a slope of $1 \%$ and plausibly clogged water discharging drainage system would not cause any damage similar to this one.

On the other hand, since a large number of lightning strikes are detected on the night of the incident. Therefore, it is judged to be necessary to investigate the effects of the impact of lightning on the structure. It is known that during a lightning strike, a significant volume of air is considerably heated up. Quite large shock forces occur due to the interaction of a large mass of hot and cold air around it, and also due to the humidity of the air and the ground, which is called the blast effect. Therefore, it is thought that these great shock forces can cause instant damage. However, in this case, it is not sufficient to explain the damage zone, since the damage is expected to be in areas that are close to the lightning rods. Whereas, the lightning rods are not nearby the damaged regions.

Furthermore, when lightning strikes a building the electric current passes through the structure which leads to a sudden heat generation and a rapid increase of temperature. The sudden heat generation may cause a fire on the building. It is thought that the sudden increase in the temperature of a significant amount of air caused by lightning may have caused the temperature of the space frame system to increase. For the purpose of understanding the underlying factors that lead to the damage shown in Figure 1, the effects of temperature change on the structure are investigated. The space frame system is given a temperature increase of $50{ }^{\circ} \mathrm{C}$. This increase is assumed to be caused by an excessively high temperature of the air during several lightning strikes. 
Based on these assumptions, $50^{\circ} \mathrm{C}$ temperature increase is applied to the global model alongside the external loads as described in the previous global analysis. A new static model is built and the results are given in Figures 18-22. Figure 18 shows the equivalent stresses of von Mises occurring in space truss systems and columns. It is seen that the stresses coming out of this figure are quite safe. However, it has been found that the stress values in the support joints reach values exceeding the safety limits and the supports reaching these values are concentrated especially in the areas where damage occurs. The reason for the great stress values in this global model is that the model is simple and gives a general idea. It would be appropriate to consider separately the situations in the bearings with large stresses.
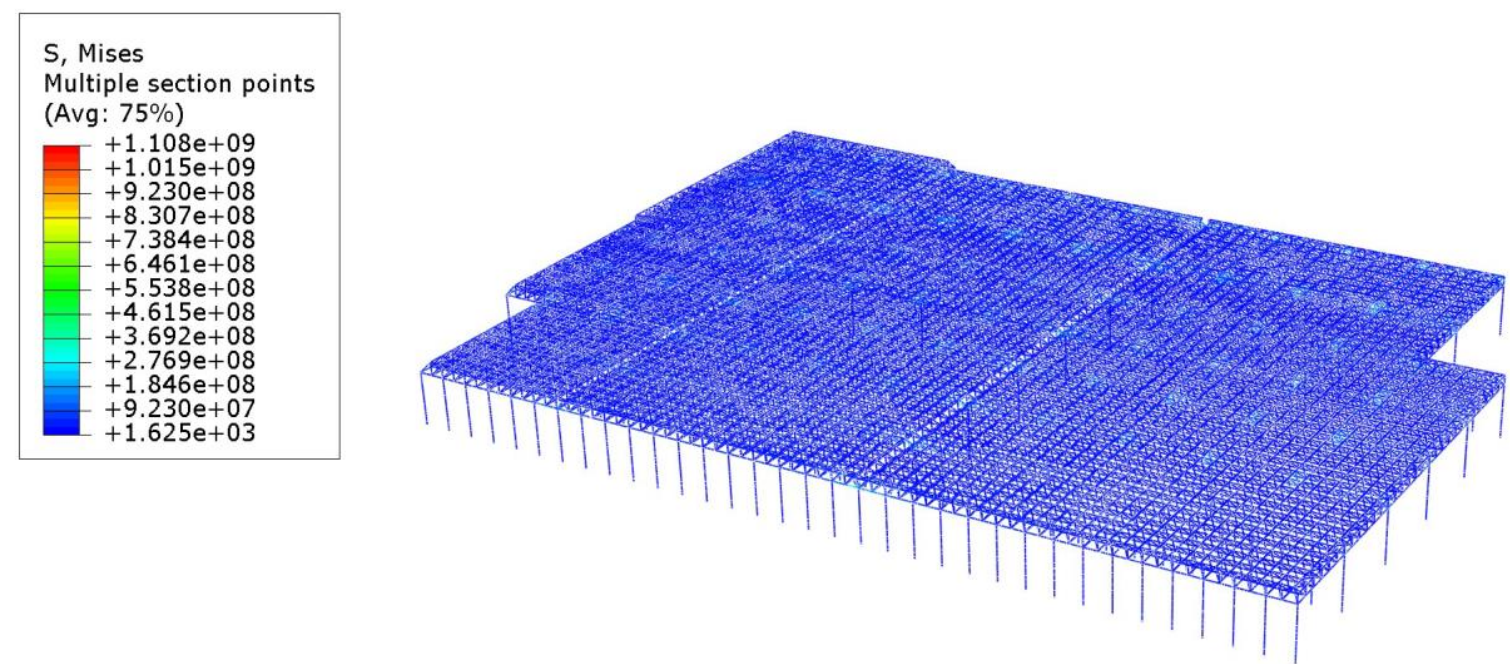

Figure 18. Stresses due to load and thermal effects in space frame and steel-reinforced concrete column system.

It is also to be noted that the " $U$ " shaped connections between the steel truss structures and the supports on the walls display the greatest stresses which is not realistic, as these connections do not exist in the real structures. Therefore, those stress values are disregarded.
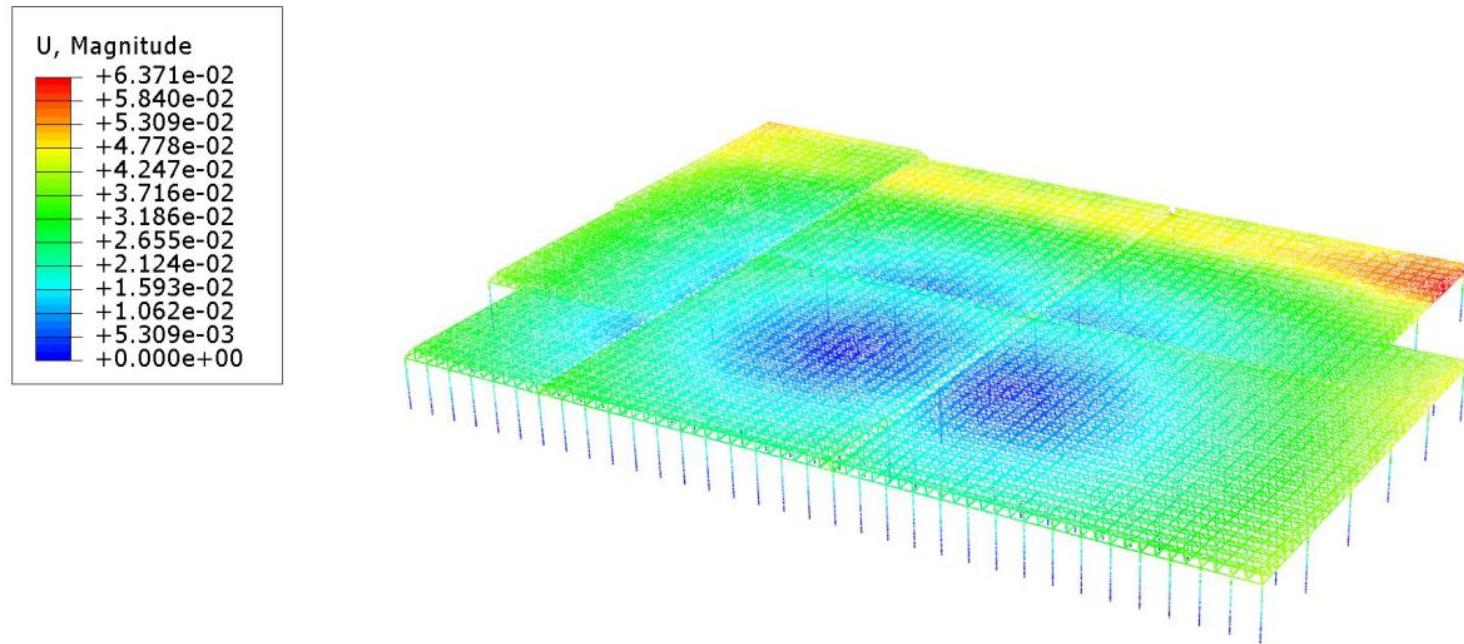

Figure 19. Resultant displacements due to load and thermal effects in space frame and steel-reinforced concrete column system.

Figure 19 shows the resultant displacements that occur throughout the system. From this figure, it can be seen that displacements are suitable and larger displacements occur in the regions where the damage occurs. 

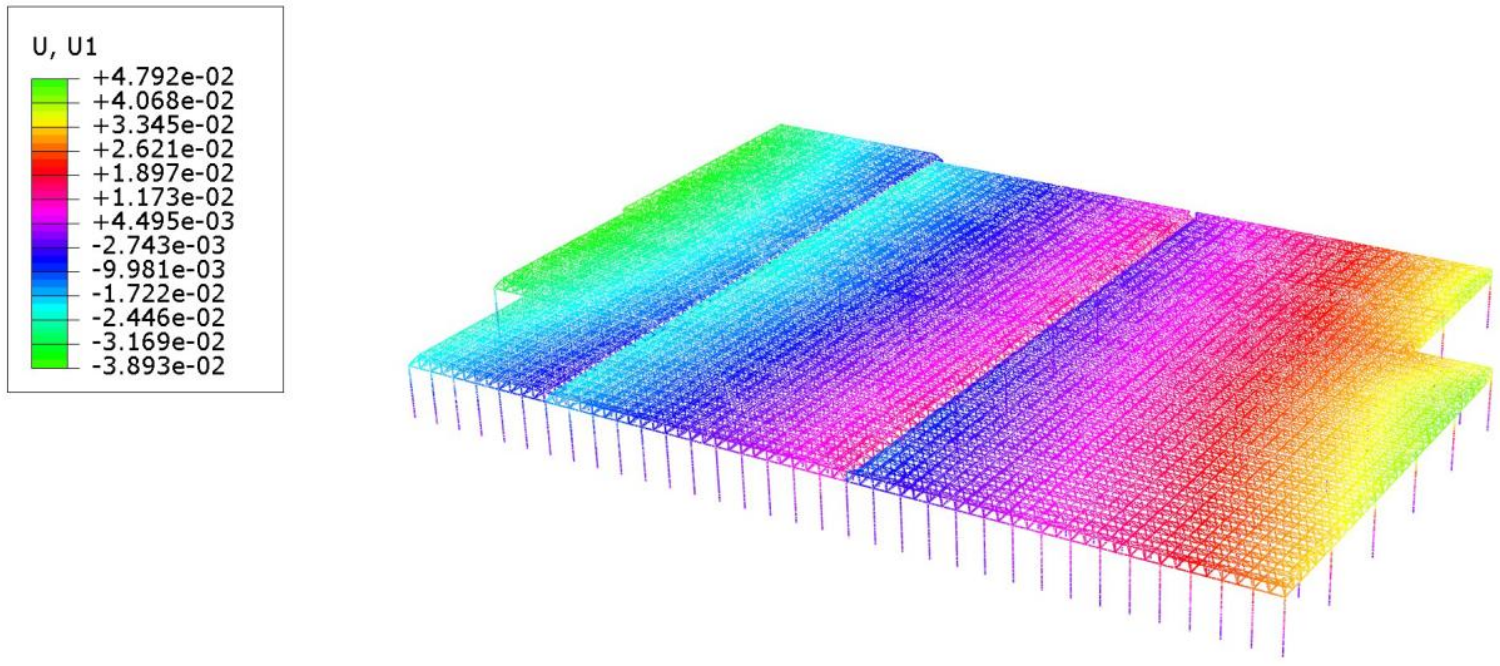

Figure 20. Displacements in the long edge direction caused by load and thermal effects in the space frame and steel-reinforced concrete column system.

Furthermore, Figure 20 shows the displacements in the long edge direction, say $x$-direction. This figure clearly shows that there are large displacements in the areas where the damage occurs. Figure 21 displays the displacements in the direction of the short edge of the building, so-called y-direction. It is to be noted that the larger displacements are observed in the direction along the shorter edge whereas the larger displacements due to thermal expansion are expected in the direction of the long edge. The reason behind it can be explained with different stiffness levels of the structure in different directions and boundary conditions of the supports. As it can be seen from Figure 6, the number of columns in the first two rows of the halls B, D, F are much more intensively positioned than the rest of the building. Moreover, the intensity of the columns in the $\mathrm{x}$-direction is greater than the intensity of columns in the y-direction. Therefore, the stiffness in the $\mathrm{x}$-direction is expected to be greater than the stiffness in the y-direction. The sliding supports and the stiffness of the structure allow the structure to deform in the $y$-direction more than $x$-direction, even though the tendency to deform is more in $\mathrm{x}$-direction than $\mathrm{y}$-direction. This leads to the storage of a larger amount of energy in the $\mathrm{x}$ direction. Additionally, since, there is no damage in the spherical supports themselves, as can be seen in Figure 16, the excessive displacements cause larger stress values in the bolt connections between the spherical parts and the members. Therefore, it is found plausible that this mechanism caused the actual failure.
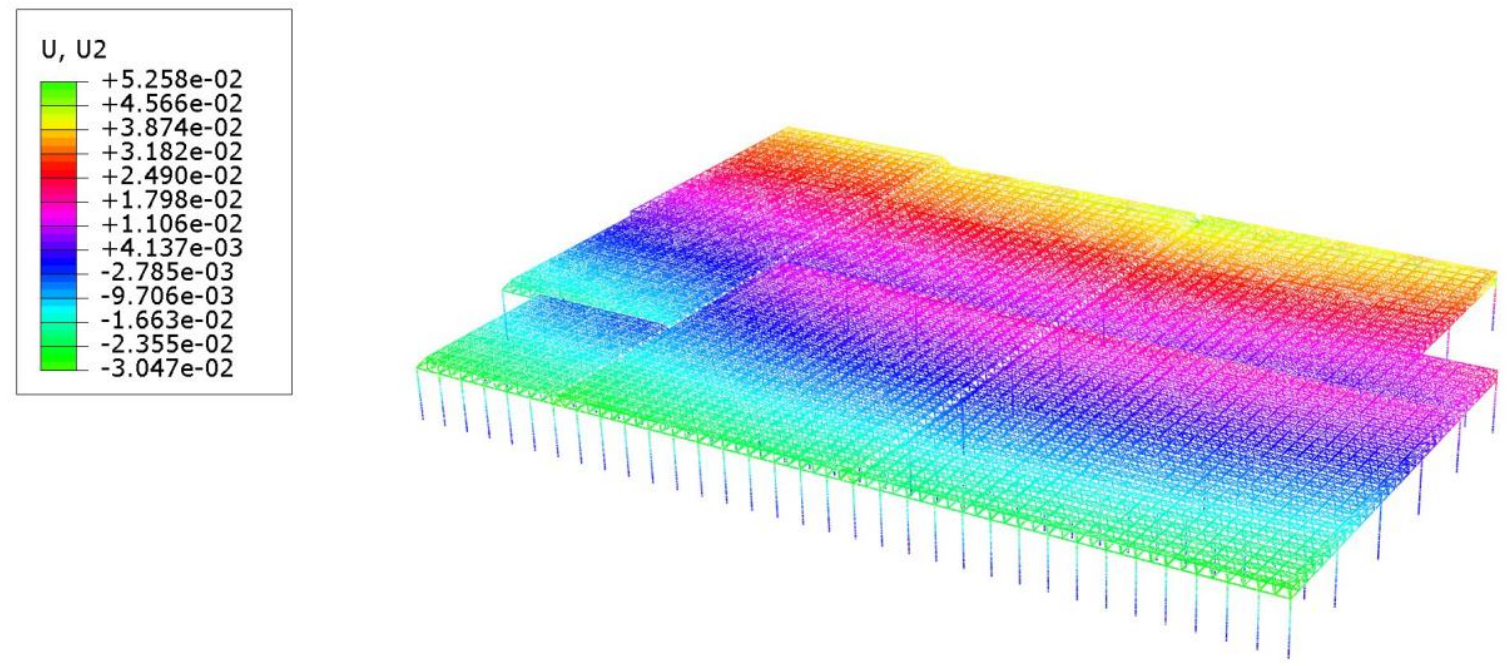

Figure 21. Displacements in the short edge direction caused by load and thermal effects in the space frame and steel-reinforced concrete column system. 
The displacements of the structure in the vertical direction given in Figure 22. Comparing the vertical displacements of the previous global analysis and this one (Figure 11 and 22), both cases display very similar distribution trends but the new one exhibits larger displacements. This lies on the facts that, there is a synergy effect based on the complex loading and the thermal expansion leads to extra loading as well as elongation in horizontal directions. On one hand, the extra loads stiffen the structure but on the other hand, elongation softens the flexural stiffness of the roof structure. Apparently, the softening becomes more dominant than the stiffening effect.
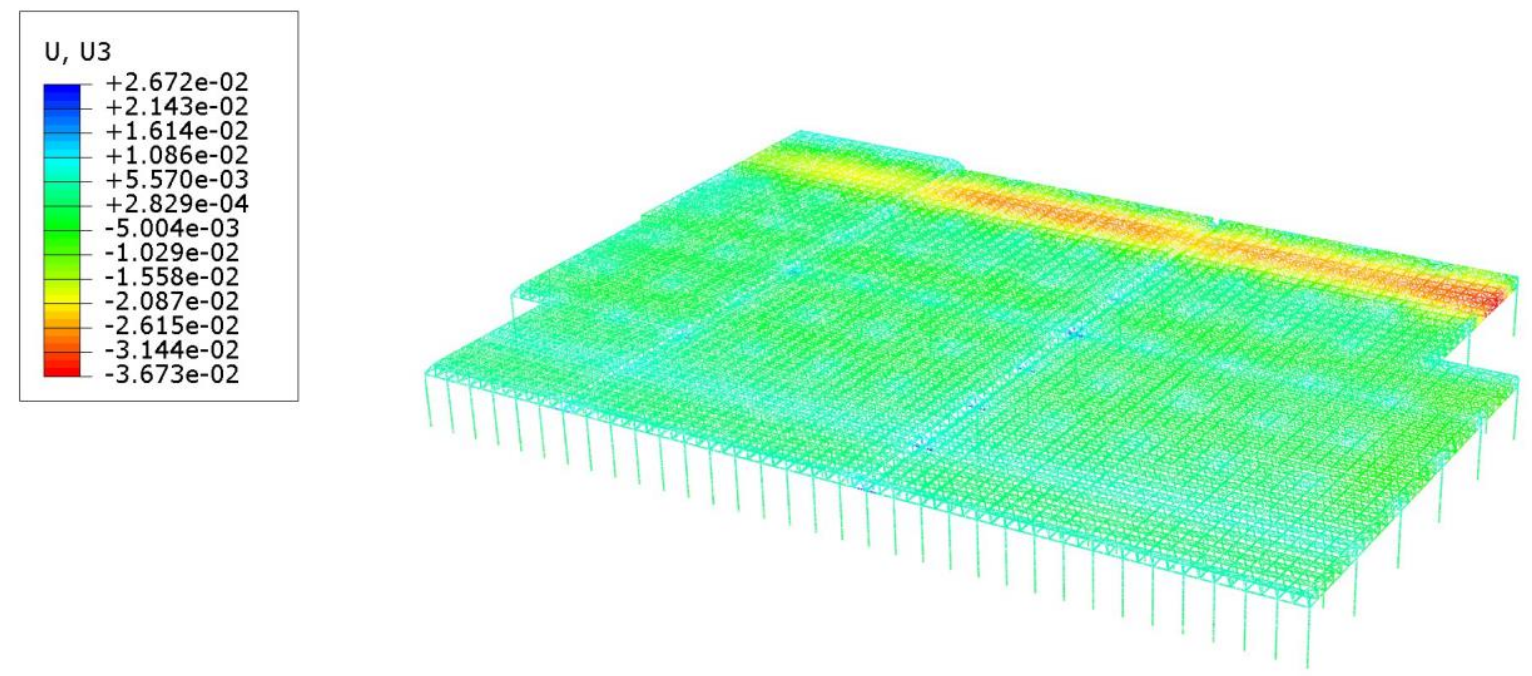

Figure 22. Displacements in the vertical direction caused by the loads in the space frame and steelreinforced concrete column system.

\section{Conclusions}

The space truss roof structure, the columns and the spherical steel supports of the factory building are put through several numerical analyses and their behaviour is evaluated. These static stress analyses are performed using the finite element method considering geometric nonlinearities. Based on the results of these simulations, a plausible explanation is made for the real failure of the structure.

According to the global analyses, the structure is quite strong and insensitive against the vertical dead loads (rain, snow, etc.) even at some higher values which are judged to be extreme and unrealistic. The most dangerous region of the space frame system in terms of vertical loads is the corridor with the largest column clearance in the A, C and E blocks. However, this region is still safe and the damage occurs somewhere else and not there.

Using the results of the global analysis, the most critical support connection is individually investigated. Based on these results, column support connections are safe as well. They are more sensitive to horizontal forces though. However, in the analysis, all the effects that create lateral forces caused by the wind and similar homogeneous distributed loads cannot make the structure exceed this safety limits and cause any damage in the locations where the real damage is. Therefore, it can be confidently stated that the structure is safe based on the standard design conventions. Thus, the results provided by the designer company are found to be consistent and appropriate.

Eliminating the possible standard horizontal loads, a new factor is taken into consideration which is expansion due to temperature change in the structure. It is judged that the expansion of structural members increases the horizontal forces at the supports and the stresses at the members. The change in temperature is assumed to be led by possible lightning strikes as it is known that there was a thunderstorm during the night when the roof collapsed. Furthermore, it is also determined by the international meteorological institutions that there were several lightning strikes in the region where the building is. The significant change of temperature of the air surrounding the lightning channel may cause heating of the roof system. The lightning at the scene caused also a sudden 
pressure change. This phenomenon is called as the blast effect. In addition to the thermal expansion, it is found possible that the blast effect may have a significant role in the failure of the structure. Testing the idea of temperature change, the damage prediction is found consistent with the real failure mode. It has been concluded that the bolts and the bolted members attached to the supports in the real damaged regions of the space truss roof system are overloaded and damaged.

Author Contributions: Conceptualization, E.T. and A.D.; methodology, E.T. and A.D.; software, M.T.; validation, E.T., A.D. and M.T.; formal analysis, M.T., E.T. and A.D.; investigation, M.T.; resources, A.D.; data curation, M.T.; writing - original draft preparation, M.T., E.T. and A.D.; writing - review and editing, M.T., E.T. and A.D.; visualization, M.T.; supervision, E.T. and A.D.; project administration, A.D.; All authors have read and agreed to the published version of the manuscript.

Conflicts of Interest: The authors declare no conflict of interest.

\section{References}

1. Wu, Z.; Rong, J.; Liu, C.; Liu, Z.; Shi, W.; Xin, P.; Li, W. Dynamic analysis of spatial truss structures including sliding joint based on the geometrically exact beam theory and isogeometric analysis. Appl. Sci. 2020, 10, doi:10.3390/app10041231.

2. Hadipriono, F.C. Analysis of Events in Recent Structural Failures. J. Struct. Eng. 1985, 111, 1468-1481, doi:10.1061/(ASCE)0733-9445(1985)111:7(1468).

3. Klasson, A.; Björnsson, I.; Crocetti, R.; Hansson, E.F. Slender Roof Structures - Failure Reviews and a Qualitative Survey of Experienced Structural Engineers. Structures 2018, 15, 174-183, doi:10.1016/j.istruc.2018.06.009.

4. Deshpande, V.S.; Fleck, N.A. Collapse of truss core sandwich beams in 3-point bending. Int. J. Solids Struct. 2001, 38, 6275-6305, doi:10.1016/S0020-7683(01)00103-2.

5. Ballarini, R.; La Mendola, L.; Le, J.L.; Monaco, A. Computational study of failure of hybrid steel trussed concrete beams. J. Struct. Eng. (United States) 2017, 143, 1-13, doi:10.1061/(ASCE)ST.1943-541X.0001792.

6. Wu, Y.; Xiao, Y. Steel and glubam hybrid space truss. Eng. Struct. 2018, 171, 140-153, doi:10.1016/j.engstruct.2018.05.086.

7. Sun, W.; Zhang, Q. Universal equivalent static wind loads of fluctuating wind loads on large-span roofs based on compensation of structural frequencies and modes. Structures 2020, 26, 92-104, doi:10.1016/j.istruc.2020.04.008.

8. Piroglu, F.; Ozakgul, K.; Iskender, H.; Trabzon, L.; Kahya, C. Site investigation of damages occurred in a steel space truss roof structure due to ponding. Eng. Fail. Anal. 2014, 36, 301-313, doi:10.1016/j.engfailanal.2013.10.018.

9. Goto, Y.; Kawanishi, N.; Honda, I. Dynamic stress amplification caused by sudden failure of tension members in steel truss bridges. J. Struct. Eng. 2011, 137, 850-861, doi:10.1061/(ASCE)ST.1943$541 X .0000338$.

10. Geis, J.; Strobel, K.; Liel, A. Snow-Induced Building Failures. J. Perform. Constr. Facil. 2012, 26, 377-388, doi:10.1061/(ASCE)CF.1943-5509.0000222. 
11. Altunişik, A.C.; Ateş, Ş.; Hüsem, M. Lateral buckling failure of steel cantilever roof of a tribune due to snow loads. Eng. Fail. Anal. 2017, 72, 67-78, doi:10.1016/j.engfailanal.2016.12.010.

12. Thai, H.T.; Kim, S.E. Nonlinear inelastic time-history analysis of truss structures. J. Constr. Steel Res. 2011, 67, 1966-1972, doi:10.1016/j.jcsr.2011.06.015.

13. Shivarudrappa, R.; Nielson, B.G.; Asce, M. Sensitivity of load distribution in light-framed wood roof systems due to typical modeling parameters. J. Perform. Constr. Facil. 2013, 27, 222-234, doi:10.1061/(ASCE)CF.1943-5509.0000323.

14. Malla, R.B.; Nalluri, B.B. Dynamic effects of member failure on response of truss-type space structures. J. Spacecr. Rockets 1995, 32, 545-551, doi:10.2514/3.26649.

15. Parisi, M.A.; Piazza, M. Seismic behavior and retrofitting of joints in traditional timber roof structures. Soil Dyn. Earthq. Eng. 2002, 22, 1183-1191, doi:10.1016/S0267-7261(02)00146-X.

16. Pollino, M.; Bruneau, M. Seismic testing of a bridge steel truss pier designed for controlled rocking. J. Struct. Eng. 2010, 136, 1523-1532, doi:10.1061/(ASCE)ST.1943-541X.0000261.

17. Sosorburam, P.; Yamaguchi, E. Seismic retrofit of steel truss bridge using buckling restrained damper. Appl. Sci. 2019, 9, doi:10.3390/app9142791.

18. Chou, C.C.; Chen, J.H. Seismic tests of post-tensioned self-centering building frames with column and slab restraints. Front. Archit. Civ. Eng. China 2011, 5, 323-334, doi:10.1007/s11709-011-0119-5.

19. Zhao, H.; Ding, Y.; Nagarajaiah, S.; Li, A. Longitudinal displacement behavior and girder end reliability of a jointless steel-truss arch railway bridge during operation. Appl. Sci. 2019, 9, doi:10.3390/app9112222.

20. Rezaei, S.; Akbari Hamed, A.; Basim, M.C. Seismic performance evaluation of steel structures equipped with dissipative columns. J. Build. Eng. 2020, 29, doi:10.1016/j.jobe.2020.101227.

21. Qu, W.L.; Chen, Z.H.; Xu, Y.L. Dynamic Analysis of Wind Excited Truss Tower With Friction Dampers. Comput. Struct. 2001, 79, 2817-2831.

22. Spyrakos, C.C.; Raftoyiannis, I.G.; Ermopoulos, J.C. Condition assessment and retrofit of a historic steeltruss railway bridge. J. Constr. Steel Res. 2004, 60, 1213-1225, doi:10.1016/j.jcsr.2003.11.004.

23. Zheng, H.D.; Fan, J. Analysis of the progressive collapse of space truss structures during earthquakes based on a physical theory hysteretic model. Thin-Walled Struct. 2018, 123, 70-81, doi:10.1016/j.tws.2017.10.051.

24. Maraveas, C.; Tsavdaridis, K.D. Assessment and retrofitting of an existing steel structure subjected to wind-induced failure analysis. J. Build. Eng. 2019, 23, 53-67, doi:10.1016/j.jobe.2019.01.005.

25. Foraboschi, P. Lateral load-carrying capacity of steel columns with fixed-roller end supports. J. Build. Eng. 2019, 26, doi:10.1016/j.jobe.2019.100879.

26. Kmet, S.; Tomko, M.; Demjan, I.; Pesek, L.; Priganc, S. Analysis of a damaged industrial hall subjected 
to the effects of fire. Struct. Eng. Mech. 2016, 58, 757-781, doi:10.12989/sem.2016.58.5.757.

27. Dwyer, J.R.; Uman, M.A. The physics of lightning. Phys. Rep. 2014, 534, 147-241, doi:10.1016/j.physrep.2013.09.004.

28. Zhivlyuk, Y.; Mandel'shtam, S. On the temperature of lightning and force of thunder. Sov. Phys. JETP $1961,13,338-340$

29. Mu, Y.; Yuan, P.; Wang, X.; Dong, C. Temperature distribution and evolution characteristic in lightning return stroke channel. J. Atmos. Solar-Terrestrial Phys. 2016, 145, 98-105, doi:10.1016/j.jastp.2016.04.013.

30. Meppelink, J. The Impact of a lightning Stroke on a Flat Roof When the Building is Filled with Water. Light. Prot. (ICLP), 1998 Int. Conf. 1998, 826-831.

31. Bothma, J.G. Transmission line tower collapse investigation: A case study. IEEE Power Energy Soc. Conf. Expo. Africa Intell. Grid Integr. Renew. Energy Resour. PowerAfrica 2012 2012, doi:10.1109/PowerAfrica.2012.6498616.

32. Usmani, A.S.; Chung, Y.C.; Torero, J.L. How did the WTC towers collapse: A new theory. Fire Saf. J. 2003, 38, 501-533, doi:10.1016/S0379-7112(03)00069-9.

33. Li, H.; Wu, G. Fatigue evaluation of steel bridge details integrating multi-scale dynamic analysis of coupled train-track-bridge system and fracture mechanics. Appl. Sci. 2020, 10, doi:10.3390/app10093261.

34. Blandford, G.E. Progressive failure analysis of inelastic space truss structures. Comput. Struct. 1996, 58, 981-990, doi:10.1016/0045-7949(95)00217-5.

35. Blandford, G.E. Review of Progressive Failure Analyses for Truss Structures. J. Struct. Eng. 1997, 123, 122-129, doi:10.1061/(ASCE)0733-9445(1997)123:2(122).

36. Malla, R.B.; Agarwal, P.; Ahmad, R. Dynamic analysis methodology for progressive failure of truss structures considering inelastic postbuckling cyclic member behavior. Eng. Struct. 2011, 33, 1503-1513, doi:10.1016/j.engstruct.2011.01.022.

37. Machaly, E.S.B. Buckling contribution to the analysis of steel trusses. Comput. Struct. 1986, 22, 445-458, doi:10.1016/0045-7949(86)90050-7.

38. Murtha-Smith, E. Alternate Path Analysis of Space Trusses for Progressive Collapse. J. Struct. Eng. 1999, 114, 1978-1999.

39. Astaneh-Asl, A. Progressive collapse of steel truss bridges, the case of I-35W collapse. 7th Int. Conf. Steel Bridg. 2008, 1-10.

40. Tanzer, A. High school gymnasium roof truss support collapse. J. Fail. Anal. Prev. 2011, 11, 208-214, doi:10.1007/s11668-011-9440-5.

41. Park, S.; Yun, C.B.; Roh, Y. Damage diagnostics on a welded zone of a steel truss member using an active sensing network system. NDT E Int. 2007, 40, 71-76, doi:10.1016/j.ndteint.2006.07.004. 
42. Riasat Azim, M.; Gül, M. Damage Detection of Steel-Truss Railway Bridges Using Operational Vibration Data. J. Struct. Eng. (United States) 2020, 146, 1-12, doi:10.1061/(ASCE)ST.1943-541X.0002547.

43. Wood, J. V.; Dawe, J.L. Full-scale test behavior of cold-formed steel roof trusses. J. Struct. Eng. 2006, 132, 616-623, doi:10.1061/(ASCE)0733-9445(2006)132:4(616).

44. Wang, H.; Ohmori, H. Elasto-plastic analysis based truss optimization using Genetic Algorithm. Eng. Struct. 2013, 50, 1-12, doi:10.1016/j.engstruct.2013.01.010.

45. Chan, S.L.; Cho, S.H. Second-order analysis and design of angle trusses Part I: Elastic analysis and design. Eng. Struct. 2008, 30, 616-625, doi:10.1016/j.engstruct.2007.05.010.

46. Cho, S.H.; Chan, S.L. Second-order analysis and design of angle trusses, Part II: Plastic analysis and design. Eng. Struct. 2008, 30, 626-631, doi:10.1016/j.engstruct.2007.04.022.

47. Iwicki, P. Stability of trusses with linear elastic side-supports. Thin-Walled Struct. 2007, 45, 849-854, doi:10.1016/j.tws.2007.08.005.

48. Bondok, D.H.; Salim, H.A. Failure capacities of cold-formed steel roof trusses end-connections. ThinWalled Struct. 2017, 121, 57-66, doi:10.1016/j.tws.2017.09.026.

49. Navaratnam, S.; Humphreys, M.; Mendis, P.; Nguyen, K.T.Q.; Zhang, K. Effect of roof to wall connection stiffness variations on the load sharing and hold-down forces of Australian timber-framed houses. Structures 2020, 27, 141-150, doi:10.1016/j.istruc.2020.05.040.

50. Fülöp, A.; Iványi, M. Experimentally analyzed stability and ductility behaviour of a space-truss roof system. Thin-Walled Struct. 2004, 42, 309-320, doi:10.1016/S0263-8231(03)00062-4.

51. Caglayan, O.; Yuksel, E. Experimental and finite element investigations on the collapse of a Mero space truss roof structure - A case study. Eng. Fail. Anal. 2008, 15, 458-470, doi:10.1016/j.engfailanal.2007.05.005.

52. Azizinamini, A. Full scale testing of old steel truss bridge. J. Constr. Steel Res. 2002, 58, 843-858, doi:10.1016/S0143-974X(01)00096-7.

53. Piroglu, F.; Ozakgul, K. Partial collapses experienced for a steel space truss roof structure induced by ice ponds. Eng. Fail. Anal. 2016, 60, 155-165, doi:10.1016/j.engfailanal.2015.11.039.

54. Pieraccini, L.; Palermo, M.; Trombetti, T.; Baroni, F. The role of ductility in the collapse of a long-span steel roof in North Italy b ) c ). Eng. Fail. Anal. 2017, 82, 243-265, doi:10.1016/j.engfailanal.2017.07.012. 